\title{
Entrepreneurial Judgment and Analysis for Successful Strategy Implementation
}

\author{
Momin Mukherjee \\ International Journal of Advanced Engineering and Management, India \\ e-mail:editorijoaem@gmail.com
}

$\begin{array}{ll}\text { Subject Category: } & \text { Management } \\ \text { Sub Category: } & \text { Strategy Management }\end{array}$

Editor:

Sahadev Roy

Volume 2 Issue 1 January 2017

Received on: 22.12.2016

Revised on: 06.01.2017

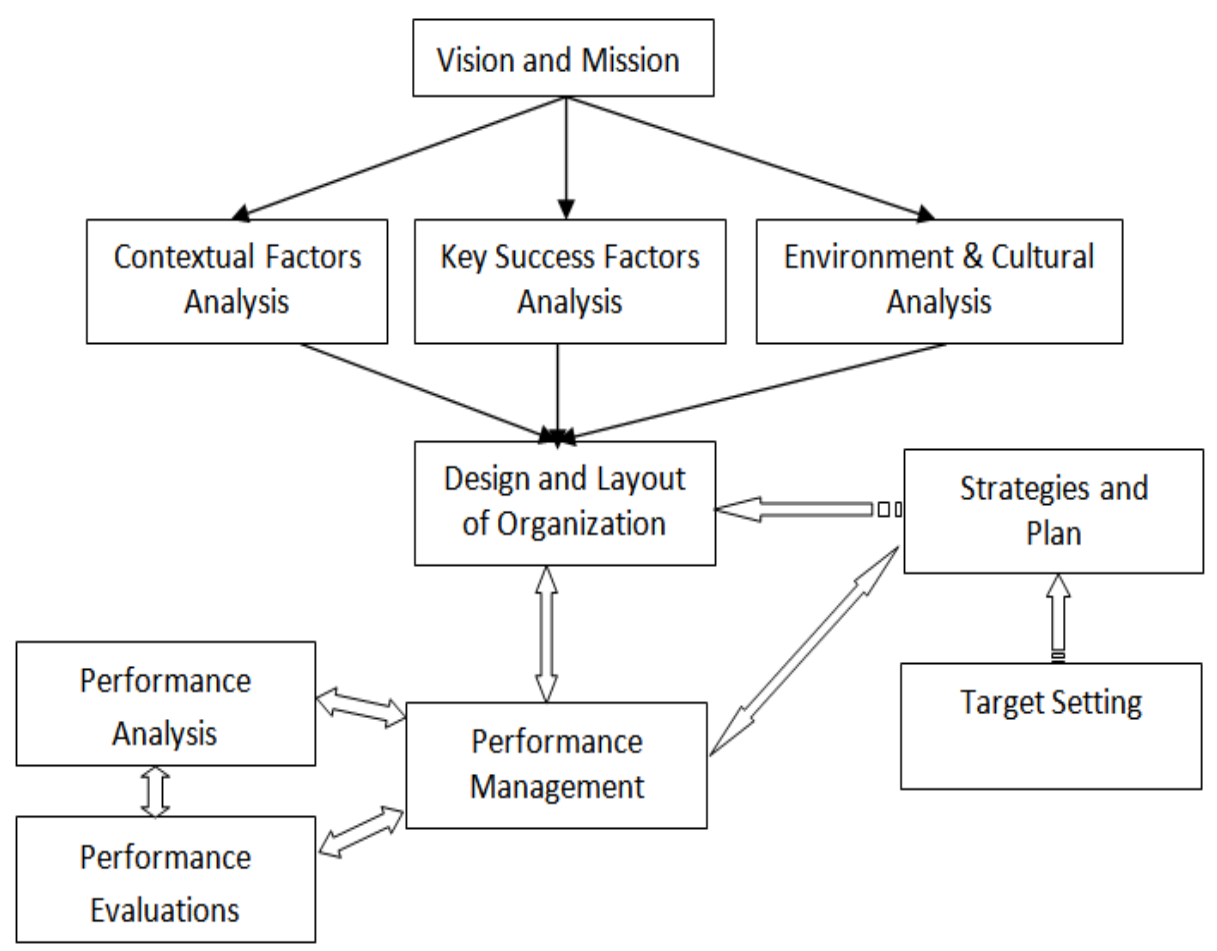

Keywords:

Dynamic organization,

Management framework;

Organizational environment;

Strategic business unit;

Strategy-formulation;

Strategic leadership.

Momin Mukherjee, "Entrepreneurial Judgment and Analysis for Successful Strategy Implementation," International Journal of Advanced Engineering and Management, Vol. 2, No. 1, pp.1-8, 2017. 


\title{
Entrepreneurial Judgment and Analysis for Successful Strategy Implementation
}

\author{
Momin Mukherjee
}

\begin{abstract}
$\underline{\text { Abstract }}$
This paper, describe the various challenges, findings, and recommendation regarding the biggest challenges of the strategies implementation. The primary purpose of this study is to describe the internal problems and external challenges of an organization. Internal problems include wrong management style/ directors' leadership, lack of proper policies regarding the organization are analysis here. The Insufficient financial resources, the unsound reward system for the staff, unstructured organization strategies, miscommunication among the employees of the organization, etc. are affecting the organization. The external challenges are an economical problem in the international market, political insecurity, improper use of government rules and regulations, external competitors in the world market, etc. are also discussed here.
\end{abstract}

\section{Introduction}

The Strategy management concept may be considered used as subjectively in the management study [1]. It may be included industry's operation, performing arts an external assessment which are carried out a different plant inspection to produce different management strategies [2]. The process is also used to perform an exterior assessment [3]. It means the whole lot may be accurately planned for target achievement, perfect location selection, implement the different new strategy, the core, and existential rationalization company's veracity by using different research methodology [4]. It must follow the philosophy of research [5]. The main characteristic of strategy formulation is to increase significantly 'vision and mission' of the target organization and also used to classify the different business's external prediction, identifying different useful interior potential as well as diverse constrained to set up and implement various strategies [6]. It also used for solving different challenging strategies for new industry also [7]. The 'Strategy formulation' processed may be utilized for the new decision to set up new businesses, funds distribution policy, whether a particular company needs to expand and exact time to entry into the international markets, etc [8]. It contains the power of execution for the essential managerial process towards the company growth [9]. Strategic leadership mostly influenced by responsible persons capable of taking decision voluntarily to make decisions precisely for the steady growth and prosperity of the target organizations for longterm achievements by maintaining long-term financial stability and improvement [10]. To adopt various changes which are necessary to meet the desired goal, all the leadership qualities are essential. Sometimes many people become a good leader, though they do not have the capability of providing direction by motivating co-worker able to maintain the growth and also strategically implementing all the required changes.

\section{Strategy Formulation}

Strategy formulation is used to determine different organizational strategic. It also helps to identify different comparative study of competitors' strengths and weak point etc. It is also an important consideration for exterior audit. Proper utilization of the internet is also useful for process time minimization by performing different exterior assessments. All business process suffered different resource constrained proper utilization of the limited resources will provide the most excellent benefit to the organization [11]. Strategy-formulation and different decision extol the production to the specific goods, property, and machineries also its marketing strategy suitable for modern civilization. Strategies imply a 'long-term' economical gain, attractive facility and customer satisfaction. Strategic decision includes various multi-functional cost analysis and also personal property management programmed for the organization. The strategy planner has the greatest standpoint towards strategic formulation and its complete resolutions.

Let s look at what strategy implementation involves:

The proposed a dynamic organization management framework is represent in Fig. 1. Contextual factor analysis, key success factor analysis and environment and cultural analysis are essential after mission and vision of the proposed model. Regular performance analysis and evolution are essential part of the performance management system. Performance analysis is also depending on strategic plan and target setting. These processes are dynamic

Momin Mukherjee, "Entrepreneurial Judgment and Analysis for Successful Strategy Implementation," International Journal of Advanced Engineering and Management, Vol. 2, No. 1, pp.1-8, 2017. 
process and organization must adopt these process this for entrepreneurial judgment and analysis for successful strategy implementation.

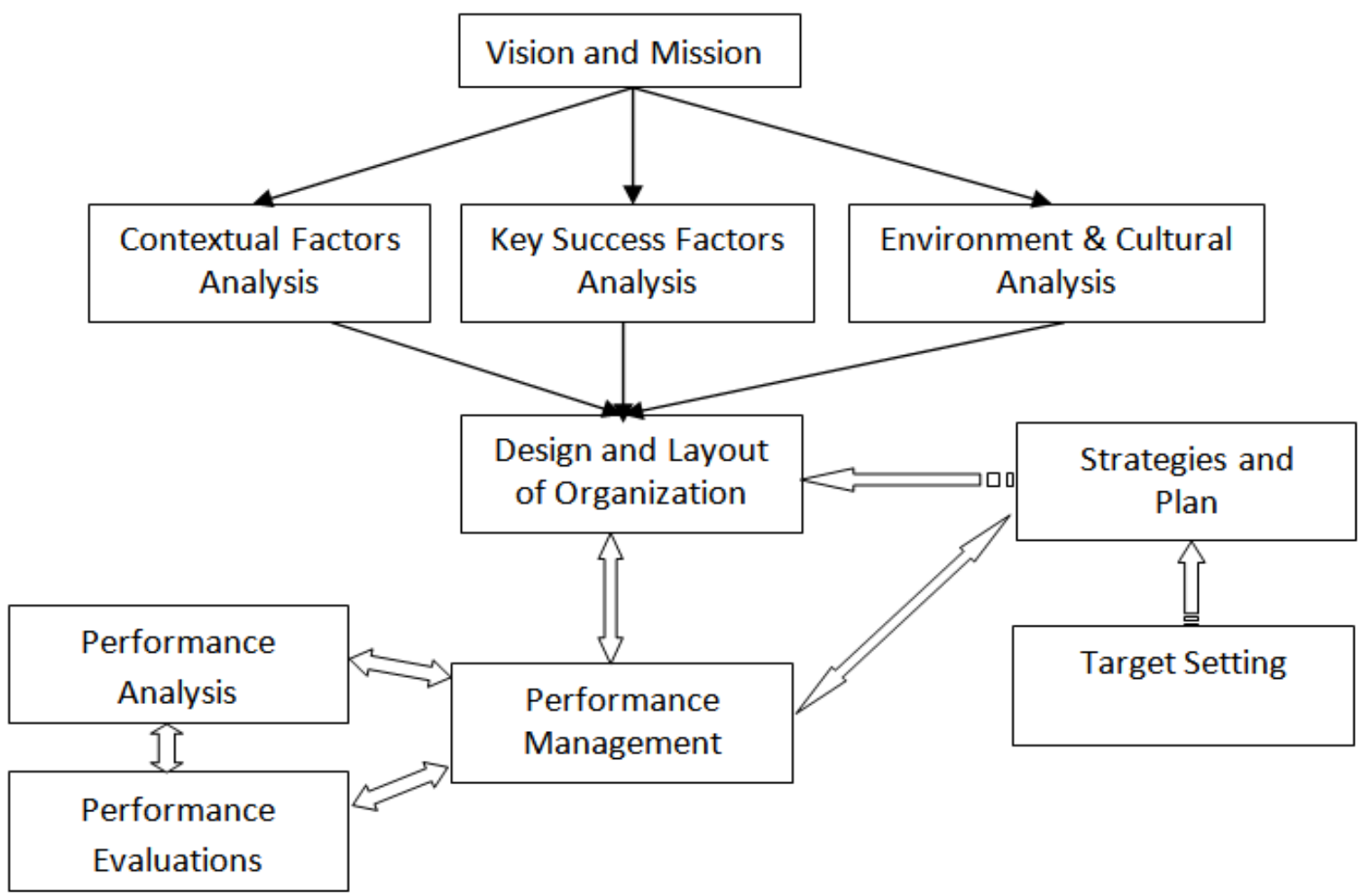

Figure 1. Dynamic Organization Management Framework.

The Strategy management concept may be considered used as subjectively in the management study. It may be included industry's operation, performing arts an external assessment which are carried out a different plant inspection to produce different management strategies [12]. The process is also used to perform an exterior assessment. It means the whole lot may be accurately planed for target achievement, perfect location selection, implement different new strategy, the core and existential rationalization company's veracity.

The main characteristic of strategy formulation is to increased significantly 'vision and mission' of the target organization and also used to classify the different business's external prediction, identifying different useful interior potential as well as different constrained to set up and implement various strategies. It also used for solving different challenging strategies for new industry also. The 'Strategy formulation' processed may be utilized for new decision to setup new businesses, funds distribution policy, whether a particular business need to expand and exact time to entry into the international markets etc [13]. It contains the power of execution for essential managerial process towards the company growth.

Strategic leadership essentially influence by responsible persons capable to take decision voluntarily to take decisions precisely for the steady growth and prosperity of the target organizations for long term achievements by maintaining long term financial stability and improvement [14]. To adopt various changes which are necessary to meet the desired goal, all the leadership qualities are essential. Sometimes many people become good leader, though they not have the capability of providing direction but by motivating co-worker able to maintain the growth and also strategically implementing all the required changes.

Strategy formulation is used to determine different organizational strategic. It also helps to identify different comparative study of competitors' strengths and weak point etc [15]. It is also an important consideration for exterior audit. Proper utilization of the internet is also useful for process time minimization by performing different exterior assessments. All business process suffered different

Momin Mukherjee, "Entrepreneurial Judgment and Analysis for Successful Strategy Implementation," International Journal of Advanced Engineering and Management, Vol. 2, No. 1, pp.1-8, 2017. 
resource constrained proper utilization of the limited resources will provide the most excellent benefit to the organization. Strategy-formulation and different decision extol the production to the specific goods, property, and machineries also its marketing strategy suitable for modern civilization. Strategies imply a 'long-term' economical gain, attractive facility and customer satisfaction. Strategic decision includes various multi-functional cost analysis and also personal property management programmed for the organization. The strategy planner has the greatest standpoint towards strategic formulation and its complete resolutions.

\section{Resource Allocation}

Every organization needed allocate their resource properly. Proper strategy management improved customer services and customer satisfaction. Proper resource distributions some time become difficult. Generally, four type resource allocation methods are followed in any business organization: by need, by merit, by social worth and by random assignment. Need allocation mainly focuses on condition that the required resources are provided to those selections that need them emergency basic [16]. An example of this is funds would be allocating to maintenance and repairing electrical hazards in the office premises. Other important resource allocations are based on Merit of the work. It is one kind of rewards to motivate those is the most productive. This may reflects in salary hike where the most creative employees get a raise while the others employee do not. Social worth allocation is also one kind of benefit for those who have the most to offer the superior for the organization or layoffs. As a common practice senior employees are avail more benefit or advantage in the company more than new ones. The most common allocation are Random distributes of the resources as per the future prediction and nature of the works.

All resources of any organizations may be classified mainly in the following category

(i) human resources, (ii) physical properties or resources, (iii) economic resources, (iv)technological resources and (v) intellectual properties or resources.

Every established organization's must capable to provide enough capital to keep up to meet the desire target.

Resource allocations are the most important factor to improve organizational growth.

Generally three approaches used for resource allocation are explain here,

- Top-Down approach: In this approach, resources are distributed from first to last a process. The CEO or Managing Director or the board of directors of the organization submits the proposed resources in different activity of the $\mathrm{n}$ organization based on the requirement.

\section{- BOTTOM-UP APPROACH}

This approach related to analysis "what are the tasks" into specific groups or department. To identify different tasks, the entire project group members analyses all required tasks to modify or upgrade the ongoing project. Ideas and tasks can be documented down on index cards. All the logically similar tasks grouped into similar categories or package. This approach provides good results, but a time-consuming procedure as compared with the other task planning methodology [17]. If any association doesn't have previous experience related to ongoing projects, this approach helps identify unknown tasks.

- Strategic budgeting: This approach is hetero type approach by mixing top to down approach and bottom to up approach.

\section{A. Criteria and Factors for Resource Allocation Process}

Main target for faithful resource allocations are expanding business and attracting more customers. Three are there criteria resource allocation are (i) risk-acceptance, (ii) support of key strategies and (iii) executive different plans. Few factors affect resource allocation mainly are (i) objective of the organization, (ii) management strategists, (iii) internal politics, (iv) external influences.

Difficulties and constraints in resource allocation

The resource allocation methodology depends on various complex strategists mainly are

- Scarcity of Resources

- Bloated demands

- Negative attitude

- Budget Battles

- Restrictions on Generating Resources

- Budgetary process

\section{Organizational Structures for Strategy Implementation}

When a new strategy is proposed or formulated, generally top management 'forgets' about the organization structure.

Momin Mukherjee, "Entrepreneurial Judgment and Analysis for Successful Strategy Implementation," International Journal of Advanced Engineering and Management, Vol. 2, No. 1, pp.1-8, 2017. 
The debate about strategy and structure has been an issue of discourse among practitioners and academics alike. It is however clear that strategy proclaims a targeted customer and market base or may be related to new product and stress generally given by which the organization will differentiate itself from their competitor. The organization structure must support the proposed strategy for such competitiveness.

The way businesses implement their strategies, is through their business processes, because they remain in the organization for a long while, not like organizational structures, that change permanently. Walking to the limit, an organization may execute certain core or strategic processes, without having its individual organizational structure. Organizational Structure in a broader sense refers to the way in which an organization is built or organized. It deals mostly with the line of authority in an organization. The structure enables the decision-maker to adopt corporate strategy which will best fit the organization under the prevailing circumstances and given available resources. On the other hand, corporate strategy is just the general possibility and direction of the organization and the process in which various businesses related operations together to achieve their desire goals. That is, corporate strategies explain the channels by which the firm carries out its said goals and objectives.

The major aspect of strategy implementation is institutionalizing proposed strategy which permeates frequent analysis and implementations in a way for long term effects. The best match between the internal structure of the organization and its strategy plans are generally manage by strategic management group. Inappropriate organizational structure can impede or prevent the desire development and also implementation of any new strategy.

Five key points needed to consider for Strategy Implementation are (i) An rigorous analysis how strategy and current structure can be matched, (ii) determine the basic elements requires to implement the proposed structure and their role in strategy implementation, (iii) analysis different alternate structural along with advantages and disadvantages of every alternate structure, (iv) analysis various factors which may influence organizational structure and (v) determine an evaluation process whether the proposed structure is appropriate or near to appropriate for implementing the proposed organization's strategy.

The informal structure may determine those are involved in decision making using fact finding techniques. An organization's strategy plan and its analysis are essential to utilize its full resources. An organization's strategy is a plan and set of action formed for specific organization. For the organization to execute proposed plans, most of the organization strategy and the structure must be compatibles with each other. General fact is the organization structure follows the predefined strategy but in actuality, the inter-relationship is nonlinear and not one directional. Sometimes it becomes more complex and both directional flows. The stockholder can't just send out a new strategy and also direction to follow everyone without analyzing its behavior. To execute such strategic plan may require huge changes within the organization. Strategy and structure are dependent to each other. A decision to change one requires an all-out effort to change the other. The structural change must be cried after the cause and effect analysis.

\section{Impact of Corporate Culture on Strategy Implementation}

The terms 'organizational culture' includes the familiar thoughts, category and also philosophy behind the friendly organizational culture. It set down the association intended for that approach. To design and develop any strategy within the organization and be implementing effectively, it should entirely support from side to side the governmental culture. Consequently, suggestion and object ought to be documented contained by an association to maintain the harmony and form a secretarial culture that embrace the organization's future plan.

\section{A. Flexibility and Adaptability}

Organizations with the intention of stays nimble are new probable to hold close renovate and breed a environment that residue release to produce and communiqué. This may offer an imitation that treatment enlightening mixture and help out give explanation approach execution. Basically all type of culture intently an involvement is able to make available numerous reasons, including coalesce element inside a relationship and make easy produce a putdown of various norms or regulations for that association.

\section{B. Characteristics of Stability}

The traditional good culture provides stability of an organization. This process methodically holds up various strategy executions. Some time, it becomes difficult to promote new business of agreement,

Momin Mukherjee, "Entrepreneurial Judgment and Analysis for Successful Strategy Implementation," International Journal of Advanced Engineering and Management, Vol. 2, No. 1, pp.1-8, 2017. 
various type of cooperation for both inter and intra organization. Sometimes, corporate culture helps to stop different illegal accomplishment, which may have advantages to improve workers mentality and coordination among them.

\section{Goal Unification}

Flexible, rough and cross culture may go in the way of strategy completion and contain a result on achievement in a positive method by behind goals. Goals can come into sight into agreement at what occasion the managerial culture ability to focal point on competence and in receipt of the organization's chief. This may convey a good message to customers on different occasion, convey extra offeres. This may produce a domino result. Sometime within the association certain unification goal appears, to achieve that goal, efforts from all level of employee may execute and collected works focus on appearance. This is the intended meaning of the business. This may permit culture to hold up few policies till completion of the primary period. For this phase of league to effort, purpose surrounds should hold up in the corporation of and be maintained by the association.

\section{Process Implementation}

Module of educational agreement and strategy execution engross expansion completion. This method includes in service acquaintance to assist rationale realization and the penalty a business is appear for while performance with customers to gather their wants. While most of the instance the harsh dilemma and supplies of a business obtain gathered, the ethnicity turns into disregarded in the method. With the intention of is wherever sequence appear strategy implementation progressively approach into continuance to support and keep on managerial culture.

\section{E. Cultural Alignment}

When cultural bring into line with the strategy accomplishment, an association is able to extra adeptly work in the worldwide marketplace. Cultures distribute managerial powerful to effort evenly separately and as group to get bigger strategic suggestion within the association. Different rigid cultural alignment some time becomes difficult. New business or re-establishing old ones, are difficult to persevere traditional cultural in the intercontinental marketplace.

\section{General framework for Strategy Implementation}

The strategic planning and its implementation process is a continuous process cycle. It included different design plan, implementation, and various evaluation methodology. Some critical assignments are the maintenance of strategic planning mechanisms by different stakeholder engagement, and alignment with the budgeting procedure. The actions, conclusion, and transactions are most critical steps and play significant role for any strategy Implementation [18] .

Mainly six the largest part any organization duties that form an decision-making accomplishment towards the execution of any strategy plan are explained here:

\section{A. Policy execution}

The organization must develops a group for disseminates, and reviews or any updates regarding this. A prescribed method which may includes purpose, scope, different roles of the target employees and their responsibilities, commitment, coordination among other colleagues and subordinate staffs. This documented procedures is basically for the smooth progress towards the execution and implementation of the policy. [19] This produce is intended to improve various security controls enhancements in the organization. The policy implementation procedure may applicable different laws, directives, executive orders by maintain different rules and regulations. Access control methodology can be developed for general purpose or for particular system, when it is essentially required for the organization. The industry is hypothetical to have the agreement necessary to circulate the policy to different stockholder for proper execution. Besides, the firm's workers ought to acquire the ability desired to perform the policy effectively.

\section{B. Finical Framework}

If the firm is to be familiar with different objectives of the strategy finical frame work is an essential part. Stockholder must provide some special subordinate those are capable to utilize additional capital proper way to fulfil desire goal. The approach has been strong-minded on, the enlightenment household tasks to be performing arts and category of necessary finale must be proper documented.

Momin Mukherjee, "Entrepreneurial Judgment and Analysis for Successful Strategy Implementation," International Journal of Advanced Engineering and Management, Vol. 2, No. 1, pp.1-8, 2017. 
Installing internal support for administrative structure: Interior method are measures and policy to establish favoured form of presentation, in sequence method to present strategy-critical in sequence on an suitable base, and whatsoever evidence, possessions organization, buyer assessment, price, and extra accounting structures are essential to afford the business important strategy-executing capability [20]. These interior systems have to continue the organization procedure, the technique the administrative in a production endeavour jointly, by means of scrutinize strategic development.

\section{Encouragement}

Rewards and various incentives which are strongly associated to the desired objectives policy and strategy. Community and division of the firm have to be objective, all through incentive, limitation, systematize, ideals, and rewards help to achieved desire target.

\section{Corporate Culture Shaping}

A strategy-supportive community culture may be motivate employees of the association to work hard with full responsibility to maintain the fame and push towards better customer service by providing quality works.

\section{E. Strategic Leadership Exercising}

Leadership exercising is an important practice for any organization. It is also a commitment to the organization to implement different strategy and its execution. It may directly involves different constructive use of power but have great responsibility. The political environments have an impact in this exercising procedure.

\section{Conclusion}

According to the above study it is established that strategy implementation strength not be successful without the proper way to use it. If it is misunderstood by the stuff or if the affected parties refuse to accept its implementation as they do not understand it, then the strategies might be failed. The best quality management style and leadership should provide for the strategies achievement in an organization, otherwise for the different types of challenges it might be close down its business. From the above study it was recognized that the leaders must consign extra importance on implementation topic in drafting their plans. Leaders of the organization must be sure about the trouble/crisis detection, explanation and responsibility illumination. There should be progress of good communication and information system, comment system, also there should be member of staff and management concern in both the implementation and formulation of the strategies success.

\section{References}

[1] A. Ferreira and D. Otley, "The Design and Use of Performance Management Systems: An Extended Framework for Analysis," Management Accounting Research, vol. 20, no. 4, pp. 263-282, 2009.

[2] M. Bertolini, M. Bevilacqua, F. E. Ciarapica and G. Giacchetta, "Development of risk-based inspection and maintenance procedures for an oil refinery," Journal of Loss Prevention in the Process Industries, vol. 22, no. 2, pp. 244-253, 2009.

[3] M. M. Bilec, R. J. Ries and H. S. Matthews, "Life-Cycle Assessment Modeling of Construction Processes for Buildings," Journal of Infrastructure Systems, vol. 16, no. 3, pp. 199-205, 2009.

[4] P. Ralph, "Software Engineering Process Theory: A Multi-Method Comparison of SensemakingCoevolution-Implementation Theory and Function-Behavior-Structure Theory," Information and Software Technology, vol. 70, pp. 232-250, 2016.

[5] T. A. Sheikh and R. Sultana, "Philosophy of Research," International Journal of Advanced Engineering and Management, vol. 1, no. 1, pp. 12-17, 2016.

[6] F. D. P. R. Perera and M. Peiró, "Strategic Planning in Healthcare Organizations," Revista Española de Cardiología (English Edition), vol. 65, no. 8, pp. 749-754, 2012.

[7] M. Mukherjee, "Object-Oriented Analysis and Design," International Journal of Advanced Engineering and Management, vol. 1, no. 1, pp. 18-24, 2016.

[8] R. Casadesus-Masanell and J. E. Ricart, "From Strategy to Business Models and onto Tactics," Long Range Planning, vol. 43, no. 2, pp. 195-215, 2010.

[9] J. Vom Brocke, A. Simons and A. Cleven, "Towards a Business Process-oriented Approach to Enterprise Content Management: The ECM-Blueprinting Framework," Information Systems and e-Business Management, vol. 9, no. 4, pp. 475-496, 2011.

[10] K. Mukherjee, "The Psychology of the Successful Entrepreneur," International Journal of Advanced Engineering and Management, vol. 1, no. 1, pp. 25-32, 2016.

Momin Mukherjee, "Entrepreneurial Judgment and Analysis for Successful Strategy Implementation," International Journal of Advanced Engineering and Management, Vol. 2, No. 1, pp.1-8, 2017. 
[11] M. R. Kramer, “Creating Shared Value,” Harvard Business Review, vol. 89, no. 1/2, pp. 62-77, 2011.

[12] B. Ä. Lundvall and B. Johnson, “The Learning Economy,” Journal of Industry Studies, vol. 1, no. 2, pp. 2342, 1994.

[13] M. Macovei, “The Austrian Business Cycle Theory: A Defense of Its General Validity," Quarterly Journal of Austrian Economics, vol. 18, no. 4, pp. 409-435, 2015.

[14] J. S. McMullen and D. A. Shepherd, "Entrepreneurial Action and the Role of Uncertainty in the Theory of the Entrepreneur," Academy of Management Review, vol. 31, no. 1, pp. 132-152, 2006.

[15] R. v. d. Meulen, November 2015. [Online]. Available: http://www.gartner.com/newsroom/id/3165317.

[16] I. K. Samaras, G. D. Hassapis and J. V. Gialelis, “A Modified DPWS Protocol Stack for 6LoWPAN-Based Wireless Sensor Networks," IEEE Transactions on Industrial Informatics, vol. 9, no. 1, pp. 209-221, 2013.

[17] P. S. Shea and D. Yanow, Interpretive Research Design:Concepts And Processes, Routledge, 2013.

[18] J. J. Wang, X. Zhao and J. J. Li, “Group Buying: A Strategic Form of Consumer Collective," Journal of Retailing, vol. 89, no. 3, pp. 338-351, 2013.

[19] J. W. Webb, G. D. Bruton, L. Tihanyi and R. D. Ireland, "Research on Entrepreneurship in the Informal Eeconomy: Framing a Research Agenda," Journal of Business Venturing, vol. 28, no. 5, pp. 598-614, 2013.

[20] M. Wheatley, Leadership and the new sceince: Discovering order in a chaoptic world, Berrett-Koehler, 2011, 3 th Edition.

Momin Mukherjee, "Entrepreneurial Judgment and Analysis for Successful Strategy Implementation," International Journal of Advanced Engineering and Management, Vol. 2, No. 1, pp.1-8, 2017. 